\title{
Tuning the flexibility of MIL-88A(Sc) through synthetic optimisation and postsynthetic halogenation
}

Catherine A. Walshe, ${ }^{[a]}$ Alexander J. R. Thom, ${ }^{[a]}$ Claire Wilson, ${ }^{[a]}$ Sanliang Ling ${ }^{[b]}$ and Ross S. Forgan*[a]

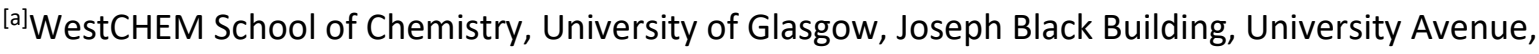
Glasgow G12 8QQ, UK

E-mail: Ross.Forgan@glasgow.ac.uk

${ }^{[b]}$ Advanced Materials Research Group, Faculty of Engineering, University of Nottingham, University Park, Nottingham NG7 2RD, UK

\begin{abstract}
Breathing behaviour in metal-organic frameworks (MOFs), the distinctive transformation between a porous phase and a less (or non) porous phase, often controls the uptake of guest molecules, endowing flexible MOFs with highly selective gas adsorptive properties. In highly flexible topologies, breathing can be tuned by linker modification, which is typically achieved pre-synthetically by the use of functionalised linkers. Herein, we show that MIL-88A(Sc) exhibits the characteristic flexibility of its topology, which can be tuned by (i) modifying synthetic conditions to yield a formate-buttressed analogue that is rigid and porous, and (ii) postsynthetic bromination across the alkene functionality of the fumarate ligand, generating a product that is rigid but non-porous. As well as providing different methodologies for tuning the flexibility and breathing behaviour of this archetypal MOF, we show that bromination of the formate-bridged analogue results in an identical material, representing a rare example of two different MOFs being postsynthetically converted to the same end product.
\end{abstract}

\section{Keywords}

Metal-organic frameworks; flexible; breathing; chemisorption; postsynthetic modification 


\section{Introduction}

Metal-organic frameworks (MOFs) have attracted increasing attention in recent years due to their versatile and highly tuneable structures, comprising metal-containing secondary building units (SBUs) linked by organic ligands. ${ }^{[1]}$ This effectively infinite set of possible combinations yields multidimensional extended frameworks that can be tailored to particular applications, notably gas storage ${ }^{[2]}$ and separation, ${ }^{[3]}$ catalysis ${ }^{[4]}$ and drug delivery. ${ }^{[5]}$ MOFs constructed using trivalent metal cations, in particular $\mathrm{Al}^{3+}, \mathrm{Fe}^{3+}$ and $\mathrm{Cr}^{3+}$, have been widely studied owing to the inherent flexibility that many of these frameworks exhibit. ${ }^{[6]}$ When combined with linear dicarboxylate linkers, they often adopt MIL-88-type structures (MIL = Materiaux de I'Institut Lavoisier), whereby the material constitutes trimeric $\left[\mathrm{M}_{3} \mathrm{O}\left(\mathrm{RCO}_{2}\right)_{6}\left(\mathrm{H}_{2} \mathrm{O}\right)_{2}(\mathrm{X})\right](\mathrm{M}=$ metal, $\mathrm{X}=$ monoanion) $\mathrm{SBU}$ s bridged by dicarboxylate linkers into the acs topology with hexagonal channels running along the crystallographic $c$ axis. ${ }^{[7]}$ This isoreticular class of materials has displayed remarkable breathing properties, swelling or contracting in response to external stimuli such as solvent immersion, pressure and temperature ${ }^{[8]}$ For example, Férey et al. reported that MIL-88A(Fe), an iron MOF constructed using fumarate linkers with formula $\left[\mathrm{Fe}_{3} \mathrm{O}\left(\mathrm{C}_{4} \mathrm{H}_{2} \mathrm{O}_{4}\right)_{3}\left(\mathrm{H}_{2} \mathrm{O}\right)_{2}(\mathrm{X})\right]$, exhibits an $85 \%$ increase in the unit cell volume between the dried, contracted form and the open, hydrated structure (Figure 1a). ${ }^{[9]}$ Other frameworks in this isoreticular series also exhibit these dynamic properties, for example MIL-88D(Cr), where the linker is biphenyl$4,4^{\prime}$-dicarboxylate (bpdc), shows a $235 \%$ increase in unit cell volume when the dried solid is immersed in pyridine. ${ }^{[10]}$

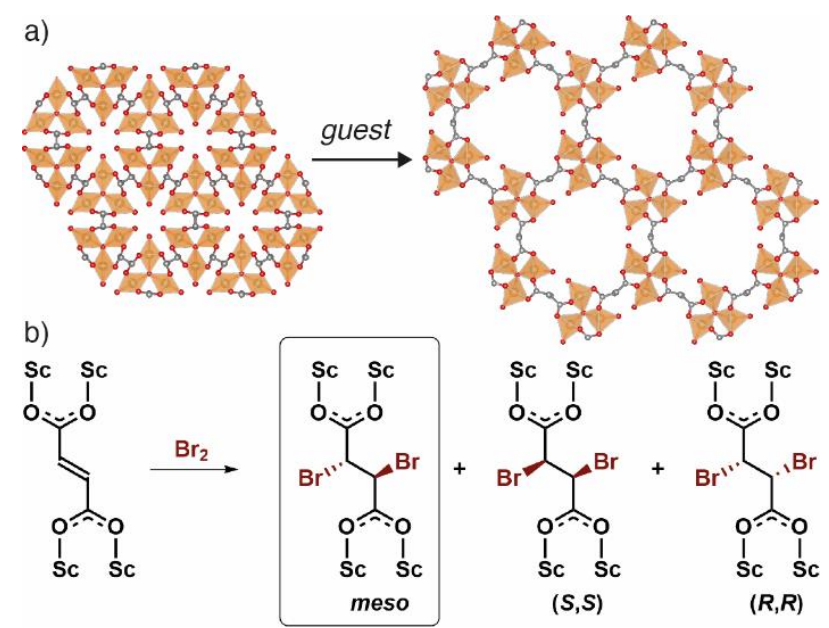

Figure 1. a) Expansion of MIL-88A(Fe) from the dried to hydrated form visualised down the crystallographic $c$ axis. Structure models redrawn from ref [9]; Fe, orange polyhedra; C, grey; O, red; $\mathrm{H}$ atoms removed for clarity. Not to scale. b) Schematic of postsynthetic bromination of the fumarate linker in MIL-88A(Sc) showing the potential products, of which the meso compound would be expected. 
The swelling capacity in these systems is primarily a function of linker length, however, this is not the only method of controlling framework flexibility; some attempts to control the breathing behaviour have focussed on linker substitution. ${ }^{[11]}$ Horcajada et al. demonstrated that when the bpdc linker in MIL-88D(Fe) is functionalised with bulky substituents such as methyl groups, the extent of breathing is reduced, as a result of the steric hindrance of the substituents reducing favourable $\pi-\pi$ interactions between linkers as the structure closes. ${ }^{[8 b]}$ Similarly, for MIL-88B(Fe), where the linker is benzene-1,4dicarboxylate, di- or tetra-substitution with bulky groups imparts permanent porosity, as the MOF cannot fully close to a non-porous form. ${ }^{\left[{ }^{[b]}\right]}$ This linker functionalization strategy has also allowed control over breathing and flexibility in a series of pillared Zn MOFs. ${ }^{[12]}$

An alternative to the direct use of functionalised linkers to form MOFs is postsynthetic modification (PSM), involving a chemical change to the framework while maintaining the overall framework crystallinity. ${ }^{[13]}$ Covalent transformations of pendant groups of the organic linkers are common; this often has an effect on gas sorption properties and occasionally, flexibility of the framework. ${ }^{[14]}$ For example, Carrington et al. have recently reported the PSM of SHF-61 (SHF = Sheffield Framework), an interpenetrated In MOF which breathes in two dimensions along the crystallographic $b$ and $c$ axes, to yield an acetamide-modified MOF, SHF-62. The additional functionality on the pendant group of SHF62 induces breathing in a third dimension, due to unfavourable interactions between amide substituents. ${ }^{[15]}$

In recent years, increasing attention has been paid to the PSM of integral units of MOF linkers. In 2009, Bauer et al. demonstrated the diastereoselective bromination of stilbene-4,4'-dicarboxylate (SDC) linkers in a Zn MOF, however, the reaction required high temperatures, which resulted in degradation and a loss of porosity. ${ }^{[16]}$ Marshall et al. later reported the halogenation of a range of chemically and mechanically stable $\mathrm{Zr}$ and $\mathrm{Hf}$ MOFs with ligands containing unsaturated units such as alkenes and alkynes, and successfully monitored their single-crystal to single-crystal transformations by single crystal X-ray diffraction. ${ }^{[17]}$ As well as in-depth characterisation of bulk microcrystalline samples, they reported that the brominated MOFs displayed a decrease in the average elastic modulus compared to the parent structures, proposing that the resultant change in hybridisation of the central carbon atoms of the linkers increases the degrees of freedom. ${ }^{[17 b]}$ Another group reported a reversible crystallineamorphous transformation of a $\mathrm{Zr}$ MOF containing the SDC linker upon bromination of the internal alkene unit, and also related this to increased linker motion. ${ }^{[18]}$

In these cases, PSM of integral unsaturated C-C bonds in the linkers has increased flexibility of the MOFs due to linker conformational change, but the underlying topologies do not breathe. To study the effect of integral PSM on a topologically flexible MOF, we selected MIL-88A, specifically the Sc(III) 
congener. Sc MOFs typically show good chemical stability, which is required to facilitate PSM, while the fumarate linker of MIL-88A(Sc) contains an accessible $\mathrm{C}=\mathrm{C}$ double bond for halogenation (Figure 1b). In addition, we have previously shown Sc MOFs to be highly amenable to modulated selfassembly, which was expected to allow access to single crystals suitable for $\mathrm{X}$-ray diffraction analysis. ${ }^{[19]}$ Herein we report the use of modulated self-assembly to synthesise MIL-88A(Sc), which we term 1, and a related, formate-bridged analogue, 2. Careful characterisation of both MOFs shows that 1 exhibits the characteristic flexibility of the MIL-88 series of MOFs, whilst $\mathbf{2}$ is rigid and permanently porous. Both MOFs can be successfully postsynthetically brominated to yield an identical final product, which further alters both flexibility and porosity.

\section{Results and Discussion}

\section{Synthesis of 1}

Initial solvothermal syntheses of highly crystalline samples of 1 were completed using scandium nitrate and fumaric acid in $\mathrm{N}, \mathrm{N}$-dimethylformamide (DMF), with ten equivalents of hydrochloric acid $(\mathrm{HCl})$ as a modulator ( $\mathrm{SI}$, Section S2). Highly crystalline powders and single crystals of 1 were reliably produced under these conditions at $100{ }^{\circ} \mathrm{C}$ for 24 hours; the single crystal structure of 1 (Figure 2a), with formula $\left[\mathrm{SC}_{3} \mathrm{O}\left(\mathrm{C}_{4} \mathrm{H}_{2} \mathrm{O}_{4}\right)_{3}\left(\mathrm{H}_{2} \mathrm{O}\right)_{2}(\mathrm{OH})\right]$, was consistent with that reported by Wang et al. during the course of our study, from crystals prepared under different reaction conditions. ${ }^{[20]}$ Once cooled to room temperature, the materials were washed with fresh DMF three times before powder X-ray diffraction (PXRD) measurements were collected, and further solvent exchange was carried out where mentioned. The PXRD pattern collected of a sample in DMF, herein known as 1as (as-synthesised) matches closely with the calculated pattern from our single crystal structure, indicating the phasepurity of the sample. SEM imaging provides further evidence of the identity of the sample (Figure $2 \mathrm{~b}$ ) where 1 as has a hexagonal rod-like morphology, consistent with reported MIL-88-type frameworks. ${ }^{[21]}$ The flexibility of the iron analogue MIL-88A(Fe) is well-reported, ${ }^{[9]}$ but was not detailed in the recent report of MIL-88A(Sc), ${ }^{[20]}$ and so, initially, attempts were made to collect single crystal structures of samples of 1as that were allowed to slowly dry in air (SI, Section S3). Unfortunately, crystal degradation meant only two reliable sets of unit cell parameters could be collected, which showed small but appreciable contractions in unit cell volume on loss of DMF solvent $(V=1700(3)$ and $1840.6(7) \AA^{3}$, respectively) compared to 1 as $\left(V=2073.8(11) \AA^{3}\right)$, while maintaining the $P 6_{3} / \mathrm{m}$ space group of the parent MOF. Comparison to the previously reported closed structure of MIL-88A(Fe), which has $V=1135 \AA^{3},{ }^{[9]}$ confirms that neither sample is fully closed. 

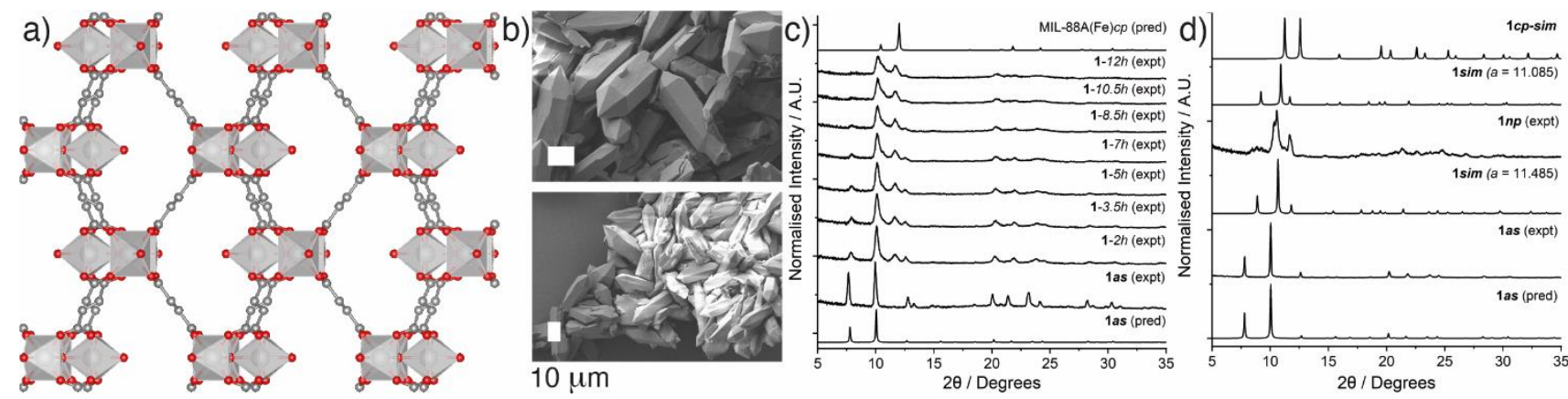

Figure 2. a) Crystal structure of 1 as viewed down the $a$ axis; Sc, silver polyhedra; $\mathrm{C}$, grey; $\mathrm{O}$, red; $\mathrm{H}$ atoms removed for clarity. b) SEM images of 1as showing characteristic hexagonal morphology. Scale bar $10 \mu \mathrm{m}$ in both. c) Stacked powder X-ray diffractograms of 1 as as it dries over time in air. d) Stacked powder X-ray diffractograms comparing DFT models to experimental data to qualitatively assess the openness of 1 np, a sample solvent exchanged in $\mathrm{MeCN}$ and dried under vacuum.

PXRD measurements were therefore carried out on bulk samples of 1as whilst they dried directly from DMF at room temperature in air (Figure 2c). 1as again contracts as residual DMF diffuses out of the pores, leading to a continuous shift of the Bragg peaks to higher $2 \theta$ angles with concomitant broadening that makes indexing the unit cell difficult. Further contraction and similar broadening of Bragg peaks are observed when 1 as is dried under vacuum from DMF. Whilst it was not possible to determine the unit cell parameters of these dried samples, comparison of diffractograms with those of MIL-88A(Fe) $)^{[9]}$ again indicate that the sample is far from fully closed.

Solvent exchange was therefore utilised to attempt to access a fully closed sample of $\mathbf{1}$. Samples of 1as were soaked in different solvents for 7 days and were exchanged with fresh solvent, before being dried overnight in a vacuum desiccator and subsequently analysed by PXRD (SI, Section S4). The dynamic behaviour of $\mathbf{1}$ is evident in PXRD patterns collected following solvation and subsequent evacuation, whereby the framework contracts to various degrees dependent on solvent. The diffractograms again show broad Bragg reflections suggesting anisotropic breathing and making indexing difficult. Density functional theory (DFT) calculations were therefore utilised to attempt to interpret the diffraction data, and a closed structural model of 1, termed $1 \mathbf{c p}$-sim, was generated (SI, Section S4). First, the open-pore structure of 1 was computationally optimised by DFT, and then further optimised under pressure, which forced the structure to undergo the open to closed phase transformation. Subsequently, the now closed-pore structure was re-optimised under ambient pressure to obtain the lattice parameters of the closed-pore structure under ambient pressure, $\mathbf{1} \boldsymbol{c p}$ $\operatorname{sim}$. The unit cell volume $\left(V=1123 \AA^{3}\right)$ is very close to that previously determined for MIL-88A(Fe) $(V$ $=1135 \AA^{3}$ ), showing its validity. ${ }^{[9]}$ To interpret the experimental powder-X-ray diffraction data, a range of structures of $\mathbf{1}$ with different unit cell volumes (i.e. at different levels of closing) was generated. 
Starting from the DFT-optimised structure $1 c p$-sim, a series of $a / b$ axes parameters, from $9.485 \AA$ to 13.485 $\AA$, was selected. Partial unit cell optimisations, i.e. only allowing the $c$ axis parameter to relax while keeping the $a / b$ cell parameters fixed during the optimisation, were performed. From this, $a$ series of structural models of 1 , named $1 \operatorname{sim}(a=\mathrm{x})$ where $\mathrm{x}=$ the fixed $a$ axis parameter, with unit cell volumes ranging from $1213 \AA^{3}$ to $2126 \AA^{3}$, was generated and used to predict powder $\mathrm{X}$-ray diffractograms as 1 closes. Qualitative comparison of powder X-ray diffractograms (Figure 2d) suggest that samples of 1as dried from both $\mathrm{EtOH}$ and $\mathrm{MeCN}$ form the most closed structures, with unit cell volumes of approximately $1600 \AA^{3}$ (a tentative Pawley refinement for a sample dried from EtOH gives a unit cell volume of $1618 \AA^{3}$, SI Figure S6) which are at intermediate levels of closure compared to 1cp-sim. ${ }^{1} \mathrm{H}$ NMR spectroscopic analysis of digested samples (SI, Figure S7) shows the attempted solvent exchanges do not successfully remove all residual DMF from the pores of $\mathbf{1}$ which we believe results in intermediate phases being accessed.

To further assess flexibility, it was attempted to swell 1 as by solvent exchange with water, which had previously produced the most open form of MIL-88A(Fe) $\left(V=2110 \AA^{3}\right) \cdot{ }^{[9]}$ PXRD analysis of a sample of las soaked in water at room temperature for one hour showed significant swelling, with a Pawley refinement giving a unit cell volume of $2410(16) \AA^{3}$ (SI, Figure S13). This suggests that, should a closed pore sample be accessible, $\mathbf{1}$ has a potentially greater amplitude of flexibility than MIL-88A(Fe), likely due to the increased ionic radius of $\mathrm{Sc}^{3+}$ compared to $\mathrm{Fe}^{3+}$. Relationships between the lengths of the crystallographic axes and unit cell volume for samples of $\mathbf{1}$ have been plotted against those previously reported for solvated MIL-88A(Fe) samples, ${ }^{[9]}$ further demonstrating the effect of ionic radius on the breathing behaviours of the two isostructural MOFs (Figure 3).

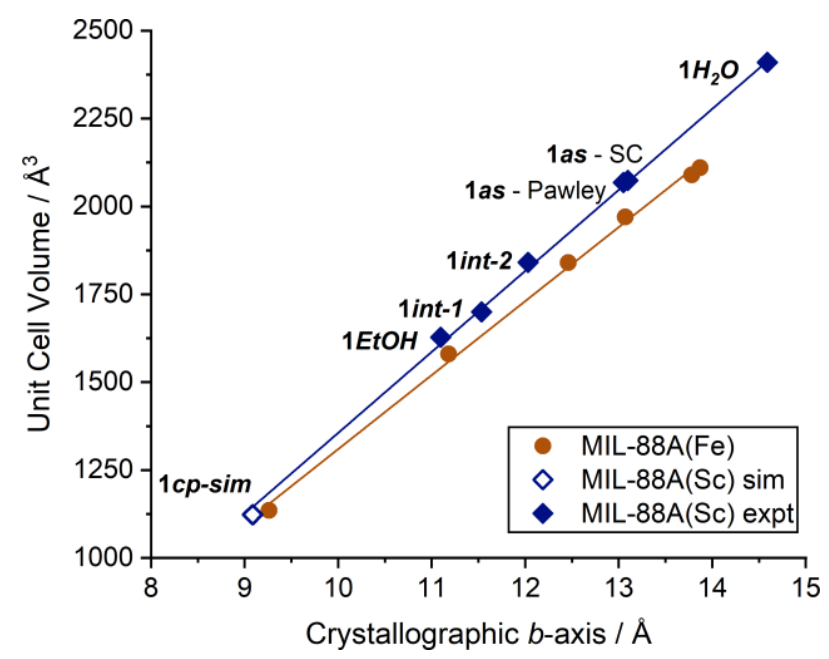

Figure 3. Plot of unit cell volume vs crystallographic $a$ axis for varying datasets collected for MIL$88 \mathrm{~A}(\mathrm{Sc})(\mathbf{1})$ compared to data previously published for MIL-88A(Fe) from ref [9]. Data are tabulated in the SI, Table S2. 
After screening several solvents of varying polarities and sizes, acetonitrile-exchanged 1as was taken forward, as MeCN reliably yields a narrow-pore material which has partially closed, and MeCN was previously used as a solvent of choice in solution-based postsynthetic halogenation of MOFs. ${ }^{[17 c]}$ This material is herein known as 1 np ( $\mathrm{np}=$ narrow pore) on which all further analyses will be based (SI, Section S5). Following further activation under vacuum at $150{ }^{\circ} \mathrm{C}$ for $20 \mathrm{~h},{ }^{1} \mathrm{H}$ NMR spectroscopic analysis of digested samples indicates 1.5 moles of DMF per $\mathrm{Sc}_{3} \mathrm{O}$ SBU remain in the pores of $1 n p$, and likely explains why a fully closed structure has not been achieved under these conditions. The presence of residual DMF is further confirmed using elemental analysis, where the measured nitrogen content of $3.23 \%$ wt correlates well with the value calculated $(3.20 \% \mathrm{wt})$ from the formula $\left[\mathrm{Sc}_{3} \mathrm{O}\left(\mathrm{C}_{4} \mathrm{H}_{2} \mathrm{O}_{4}\right)_{3}\left(\mathrm{H}_{2} \mathrm{O}\right)_{2}(\mathrm{OH})\right] \cdot\left(\mathrm{C}_{3} \mathrm{H}_{7} \mathrm{NO}\right)_{1.5}$. TGA measurements were carried out in air, to understand the thermal stability of 1 and further probe the solvent content. 1 exhibited a high thermal stability, with degradation of the framework occurring at $460{ }^{\circ} \mathrm{C}$, resulting in a residual mass of $31.0 \% \mathrm{wt}$ when normalised to remove contribution from adsorbed water below $100{ }^{\circ} \mathrm{C}$. This is concordant with an expected $\mathrm{Sc}_{2} \mathrm{O}_{3}$ residue of $31.5 \%$ for the above formula predicted by elemental analysis and NMR spectroscopy.

The characteristic anisotropic breathing behaviour in MIL-88-type frameworks often underpins their investigation for gas capture/separation applications. ${ }^{[22]}$ However, a combination of the contraction of 1 and the residual DMF in the pores results in limited nitrogen adsorption at $77 \mathrm{~K}$; following activation at $150^{\circ} \mathrm{C}$ under vacuum for $20 \mathrm{~h}$, there is minimal $\mathrm{N}_{2}$ uptake by $\mathbf{1 n p}$. In contrast, 1 np displays reasonable $\mathrm{CO}_{2}$ adsorption $-2.4 \mathrm{mmol} \mathrm{g}^{-1}$ at 1 bar at $273 \mathrm{~K}$ - which is comparable with other reported Sc MOFs. ${ }^{[23]}$ In the absence of polar functional groups in a MOF, reports have indicated that $\mathrm{CO}_{2}$ uptake can be improved by tuning pore size using smaller linkers. ${ }^{[24]} 1 \mathrm{np}$ also achieves a modest $\mathrm{H}_{2}$ adsorption of $1.3 \mathrm{wt} \%$, which is relatively unremarkable when compared with other reported Sc-MOFs. ${ }^{[8 d, 25]}$

\section{Synthesis of $\mathbf{2}$}

During synthetic optimisations, a new Sc-fumarate MOF named 2, with an orthorhombic unit cell ( $a=$ 17.0967(9), $b=15.1239(9), c=12.2795(7))$, was discovered at higher synthesis temperatures $\left(150^{\circ} \mathrm{C}\right)$ with scandium nitrate and fumaric acid, again in DMF but with one equivalent of $\mathrm{HCl}$ as modulator (SI, Section S6). The framework has the same trigonal prismatic SBU as 1, where three scandium centres are linked by one $\mu_{3}-\mathrm{O}^{2-}$ centre and capped by carboxylate groups from the fumaric acid linkers, with the same underlying connectivity (Figures $4 a, 4 b$ ). However, each cluster is now bridged to two others by formate anions coordinated to axial Sc positions, which replace the terminal $\mathrm{OH}$ anions and one of the two coordinating water ligands of $\mathbf{1}$. Only one of the three $\mathrm{Sc}^{3+}$ ions in the SBU has axially coordinated solvent - a 1:1 ratio of occupationally disordered water and $O$-coordinated DMF (itself 
disordered over two positions) - with each water ligand hydrogen bonding to a further pore-bound DMF molecule to yield a material with overall formula $\left[\mathrm{SC}_{3} \mathrm{O}\left(\mathrm{C}_{4} \mathrm{H}_{2} \mathrm{O}_{4}\right)_{3}(\mathrm{HCOO})\left(\mathrm{H}_{2} \mathrm{O}\right)_{0.5}\left(\mathrm{C}_{3} \mathrm{H}_{7} \mathrm{NO}\right)_{0.5}\right] \cdot\left(\mathrm{C}_{3} \mathrm{H}_{7} \mathrm{NO}\right)_{0.5}$. This formate bridging is similar to that observed by Wei et al. in rare-earth MOFs with underlying MIL-88 topologies, whereby the trinuclear SBUs are interconnected by $\mathrm{HCOO}^{-}$groups to enhance chemical and thermal stability, ${ }^{[26]}$ but these examples, with benzene-1,4-dicarboxylate and naphthalene-2,6-dicarboxylate ligands, differ in overall connectivity and coordination compared to 2 . Most recently, formate bridged $\mathrm{Sc}_{3} \mathrm{O}$ trimers have been reported by Prasad et al. when synthesising Sc-BTB (BTB = benzenetribenzoate, or 1,3,5-tris(4carboxyphenyl)benzene) resulting in a chain-like SBU, rather than independent trimers. ${ }^{[23 a]}$ They reported that the formate groups are a direct result of the hydrolysis of DMF at higher temperatures in the presence of acid, similar to the synthetic conditions employed to prepare $\mathbf{2}$.
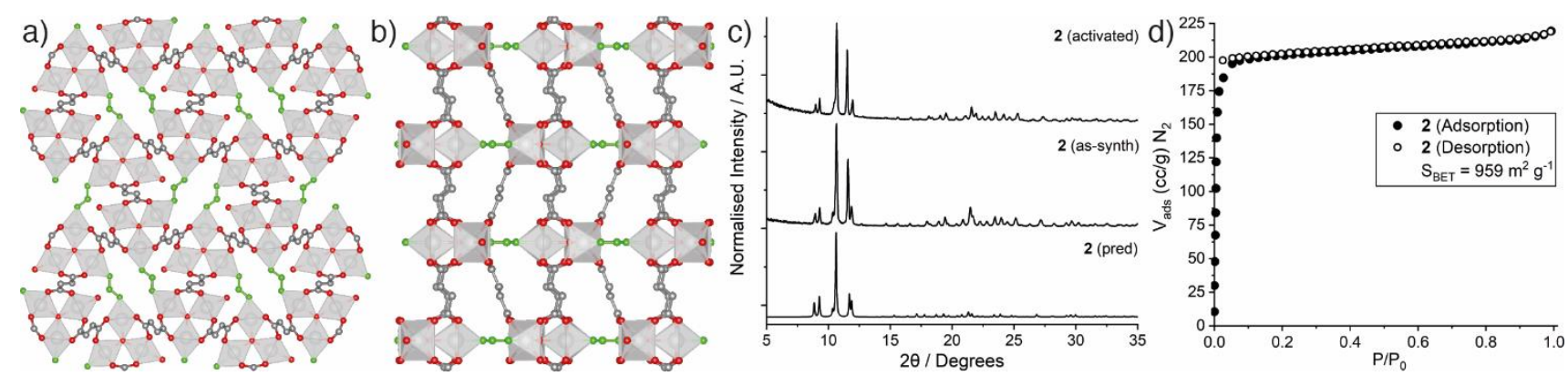

Figure 4. Crystal structure of $\mathbf{2}$ as viewed down a) the crystallographic $b$ axis and b) crystallographic $c$ axis; Sc, silver polyhedra; $\mathrm{C}$, grey; $\mathrm{O}$, red; formate bridges, green; $\mathrm{H}$ atoms and pore solvents removed for clarity. c) Stacked powder X-ray diffractograms of $\mathbf{2}$ as-synthesised, and after activation at $150{ }^{\circ} \mathrm{C}$ under vacuum, compared to that predicted from the crystal structure, showing its rigidity. d) $\mathrm{N}_{2}$ adsorption/desorption isotherms (77 K) of an activated sample of 2.

Following synthesis, $\mathbf{2}$ was washed in fresh DMF three times, and subsequently by fresh acetonitrile three times, and dried under vacuum overnight before further analysis. The PXRD pattern for a bulk sample of this as-synthesised $\mathbf{2}$ closely matches the calculated pattern generated from the single crystal structure (Figure 4c). The ${ }^{1} \mathrm{H}$ NMR spectrum of a digested sample confirms the presence of formate and DMF in expected quantities, while elemental analysis and TGA further support the bulk composition matching that of the crystal structure ( $\mathrm{SI}$, Section S6). The TGA profile reveals that $\mathbf{2}$ is thermally stable until approximately $370{ }^{\circ} \mathrm{C}$, where it exhibits a large mass loss relating to the decomposition of the framework. This is similar to the thermal activity exhibited by $\mathbf{1}$, however, the cleavage of the formate bridges induces a faster break down of the MOF at lower temperatures. As previously discussed, MOFs in the MIL-88 series are well-known for their flexible behaviour, however, following evacuation under vacuum at $150{ }^{\circ} \mathrm{C}$, no changes are apparent in the powder $\mathrm{X}$-ray 
diffractogram of $\mathbf{2}$, suggesting the formate bridges buttress the structure and do not allow it to close (Figure 4c). As such, 2 exhibits a type I isotherm for $\mathrm{N}_{2}$ adsorption at $77 \mathrm{~K}$, with a relatively high BET surface area $\left(S_{\mathrm{BET}}=959 \mathrm{~m}^{2} \mathrm{~g}^{-1}\right.$, Figure $\left.4 \mathrm{~d}\right)$, and also displays good $\mathrm{CO}_{2}$ adsorption $-2.7 \mathrm{mmol} \mathrm{g}^{-1}$ at 1 bar at $273 \mathrm{~K}$ - which is comparable to other scandium MOFs (SI, Figure S25). ${ }^{[23]} 2$ also shows comparable $\mathrm{H}_{2}$ adsorption to $1 n p$, achieving an uptake of $1.36 \mathrm{wt} \%$. Incorporation of the formate bridges has imparted rigidity to 2 , preventing the framework from flexing and closing, therefore eradicating the dynamic behaviour exhibited by 1 .

\section{Synthesis of 1-Br}

With the flexible $\mathbf{1}$ and the rigid $\mathbf{2}$ in hand, we sought to examine the effect of postsynthetic bromination of the fumarate linkers on the flexibility of both MOFs. Postsynthetic bromination reactions are often carried out on suspensions of the MOF in organic solvents, ${ }^{[16-17]}$ however, here we report the use of direct vapour diffusion to induce bromination, which we had previously used for postsynthetic iodination. ${ }^{[17 c]}$ While carrying out this work, a similar method was reported by Matemb Ma Ntep et al. to brominate acetylenedicarboxylate linkers in a Ce(IV) MOF. ${ }^{[27]} \mathbf{1 n p}$ and bromine liquid were added to separate, uncapped vials that were sealed in a closed vessel and allowed to react at room temperature for 48 hours in darkness (SI, Section S7). The resulting material, which we have termed $\mathbf{1}-\mathrm{Br}_{2}$, was subsequently washed in acetonitrile to remove excess bromine from the pores and dried at room temperature under vacuum for further analysis. Concurrently, single crystals of 1as were suspended in acetonitrile and $\mathrm{Br}_{2}$ added directly; the resultant single-crystal to single-crystal transformation allowed the collection of the single crystal structure of $1-\mathbf{B r}_{2}$ (Figure $5 \mathrm{a}$ ).

The single crystal structure of $\mathbf{1}-\mathrm{Br}_{2}$ reveals that brominated MOF retains the same hexagonal space group $\mathrm{P}_{3} / \mathrm{m}$ as the parent $\mathrm{MOF}, \mathbf{1 a s}$. The chemical transformation to $1-\mathrm{Br}_{2}$ results in a small contraction along the $c$ axis, from $13.958(4) \AA$ to $13.538(1) \AA$, and a subsequent minor increase in unit cell volume from $2073.8(11) \AA^{3}$ to $2088.4(5) \AA^{3}$. The bromine units are clearly visible, with two equally occupied linker conformations evident in the disorder model (Figure 5b). PXRD patterns of bulk samples prepared by vapour phase bromination also confirm that there is a clear transformation from 1np to $1-\mathrm{Br}_{2}$. The PXRD pattern for $1-\mathrm{Br}_{2}$ calculated from the crystal structure exhibits a close match to the experimental diffractogram (Figure $5 \mathrm{c}$ ), and the structural transition is confirmed by Pawley refinement (SI, Figure S27), indicating the bulk sample has been successfully brominated with high phase purity. 

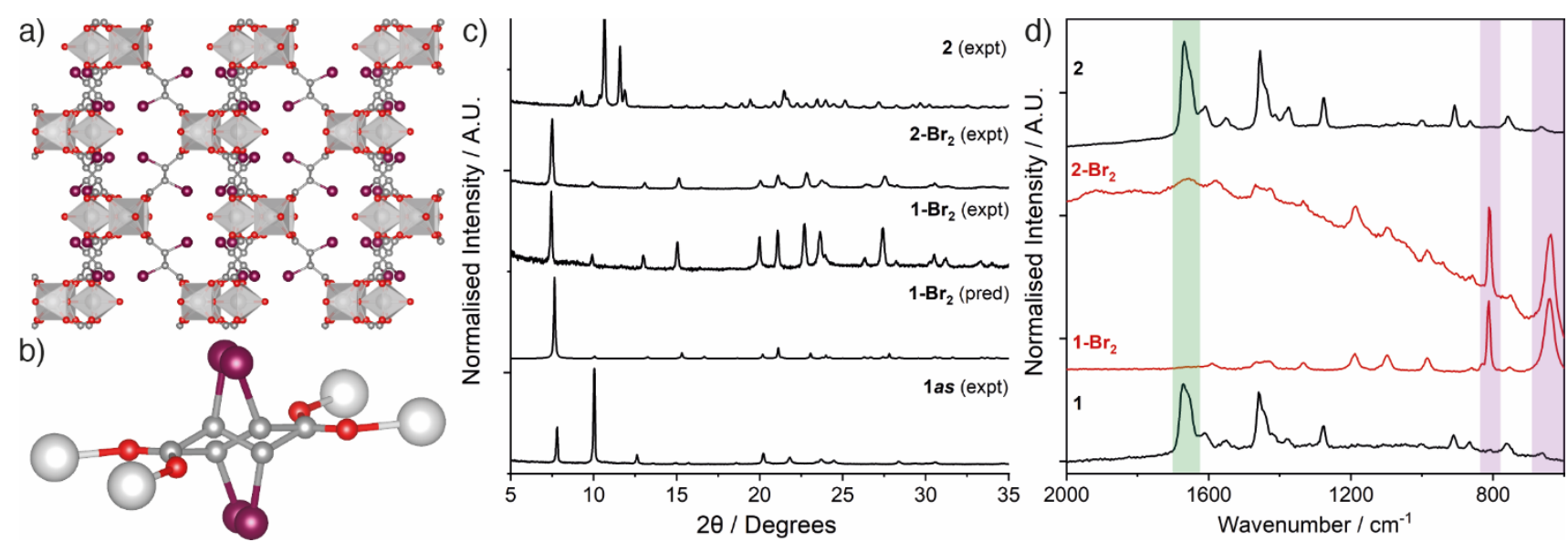

Figure 5. a) Crystal structure of $\mathbf{1}-\mathrm{Br}_{2}$ viewed down the crystallographic $a$ axis; Sc, silver polyhedra; $\mathrm{C}$, grey; $\mathrm{O}$, red; $\mathrm{Br}$, purple; disorder and $\mathrm{H}$ atoms removed for clarity. b) Disorder in the brominated linker in the crystal structure of $\mathbf{1}-\mathrm{Br}_{2}$; $\mathrm{Sc}$ represented as silver spheres; $\mathrm{H}$ atoms removed for clarity. $\mathrm{c}$ ) Stacked powder X-ray diffractograms, and d) stacked Raman spectra showing conversion of $\mathbf{1}$ and $\mathbf{2}$ into identical brominated products, $\mathbf{1}-\mathbf{B r}_{\mathbf{2}}$ and $\mathbf{2}-\mathbf{B r}_{2}$, respectively. The green box highlights the band assigned to the $\mathrm{C}=\mathrm{C}$ bond in $\mathbf{1}$ and $\mathbf{2}$ around $1650 \mathrm{~cm}^{-1}$, while the purple boxes highlight the bands assigned to the $\mathrm{C}-\mathrm{C}\left(\sim 800 \mathrm{~cm}^{-1}\right)$ and $\mathrm{C}-\mathrm{Br}\left(\sim 650 \mathrm{~cm}^{-1}\right)$ bonds in 1-1- $\mathrm{Br}_{2}$ and $\mathbf{2}-\mathrm{Br}_{2}$. The broad feature in the spectrum of $\mathbf{2}-\mathbf{B r}_{\mathbf{2}}$ is associated with laser-induced sample degradation.

The chemical transformation can also be monitored by Raman spectroscopy, where the alkene $(C=C)$ band at $1670 \mathrm{~cm}^{-1}$ disappears upon full bromination of the structure, alongside appearance of a strong band at $641 \mathrm{~cm}^{-1}$ which is indicative of the $\mathrm{C}-\mathrm{Br}$ stretch (Figure $5 \mathrm{~d}$ ). Quantitative conversion to $1-\mathrm{Br}_{2}$ is also evident through ${ }^{1} \mathrm{H}$ and ${ }^{13} \mathrm{C}$ NMR spectroscopy of acid-digested $\left(\mathrm{D}_{2} \mathrm{SO}_{4} / \mathrm{DMSO}-d_{6}\right)$ samples. The disappearance of the resonance at $\delta=6.6 \mathrm{ppm}$, assigned to the alkene protons of fumarate, and the emergence of a singlet at $\delta=4.5 \mathrm{ppm}$ in the ${ }^{1} \mathrm{H}$ NMR spectrum of $1-\mathrm{Br}_{2}$ indicates that $1 \mathrm{np}$ has been fully and stereoselectively brominated to the expected meso product. ${ }^{[28]}$ Similarly, in the ${ }^{13} \mathrm{C}$ NMR spectrum of $1-\mathrm{Br}_{2}$, the emergence of a peak at $\delta=42 \mathrm{ppm}$ and disappearance of peak at $\delta=134 \mathrm{ppm}$ indicates the change in hybridisation of the alkene carbon atom upon bromination, from $s p^{2}$ to $s p^{3}$ (see SI, Figures S29 and S30) The ${ }^{1} \mathrm{H}$ NMR spectrum indicates that the pore bound DMF from 1as has been retained through the bromination process, giving an overall formula of $\left[\mathrm{Sc}_{3} \mathrm{O}\left(\mathrm{C}_{4} \mathrm{H}_{2} \mathrm{O}_{4} \mathrm{Br}_{2}\right)_{3}\left(\mathrm{H}_{2} \mathrm{O}\right)_{2}(\mathrm{OH})\right] \cdot\left(\mathrm{C}_{3} \mathrm{H}_{7} \mathrm{NO}\right)_{1.5}$. Chemical modification is also evident using TGA; when residual weakly-absorbing solvents are removed, the $\mathrm{Sc}_{2} \mathrm{O}_{3}$ residue $(17.5 \% \mathrm{wt})$ is close to that expected for the above formula (18.2\% wt). Elemental analysis, however, gave $\mathrm{C}$ and $\mathrm{N}$ contents lower than would be expected, correlating more closely with only one DMF molecule per SBU and adsorption of one water molecule, suggesting a formula of $\left[\mathrm{Sc}_{3} \mathrm{O}\left(\mathrm{C}_{4} \mathrm{H}_{2} \mathrm{O}_{4} \mathrm{Br}_{2}\right)_{3}\left(\mathrm{H}_{2} \mathrm{O}\right)_{2}(\mathrm{OH})\right] \cdot \mathrm{C}_{3} \mathrm{H}_{7} \mathrm{NO} \cdot \mathrm{H}_{2} \mathrm{O}$ for this particular sample; the theoretical bromine content from this composition ( $42.9 \% \mathrm{wt}$ ) correlates well with the experimentally measured value of $45.7 \%$ wt. 
Taken together, these comprehensive structural, spectroscopic, and compositional experiments confirm quantitative bromination of 1 np. Whilst $1 n p$ does not adsorb $N_{2}$, the fact that bromination occurs throughout the bulk of the material in the vapour phase experiment confirms the pores are accessible to the larger $\mathrm{Br}_{2}$ molecule, but not to $\mathrm{N}_{2}$. One hypothesis could be greater adsorbentadsorbate interactions opening the pores, or alternatively bromination occurs at the particle surface, beginning to open the pores and allowing $\mathrm{Br}_{2}$ to penetrate further into the material to react and open adjacent pores.

Whilst the addition of the bromine moieties across the unsaturated bond and subsequent change in hybridisation of the linker carbon atoms from $s p^{2}$ to $s p^{3}$ may be expected to increase flexibility, bromination of 1 actually imparts rigidity to the framework. Unlike $1 \mathbf{n p}, \mathbf{1 - B r _ { 2 }}$ shows no change in powder X-ray diffractograms when dried from, or soaked in, various solvents over an extended time. Even following activation for 20 hours at $150{ }^{\circ} \mathrm{C}$ under vacuum, the framework shows no crystallographic changes according to PXRD (Figure 6). It is likely that the bulky bromine groups are sterically sufficient to prevent the framework from closing under ambient conditions. Despite the rigidity of $1-\mathrm{Br}_{2}$, it would appear that the bromine units sterically block the pores, and so $\mathrm{N}_{2}$ uptake at $77 \mathrm{~K}$ and 1 bar is negligible. Nevertheless, this PSM methodology yields a MOF with new chemical functionality and modified breathing behaviour, a change which, in this instance, could not have been achieved through solvent exchange alone.

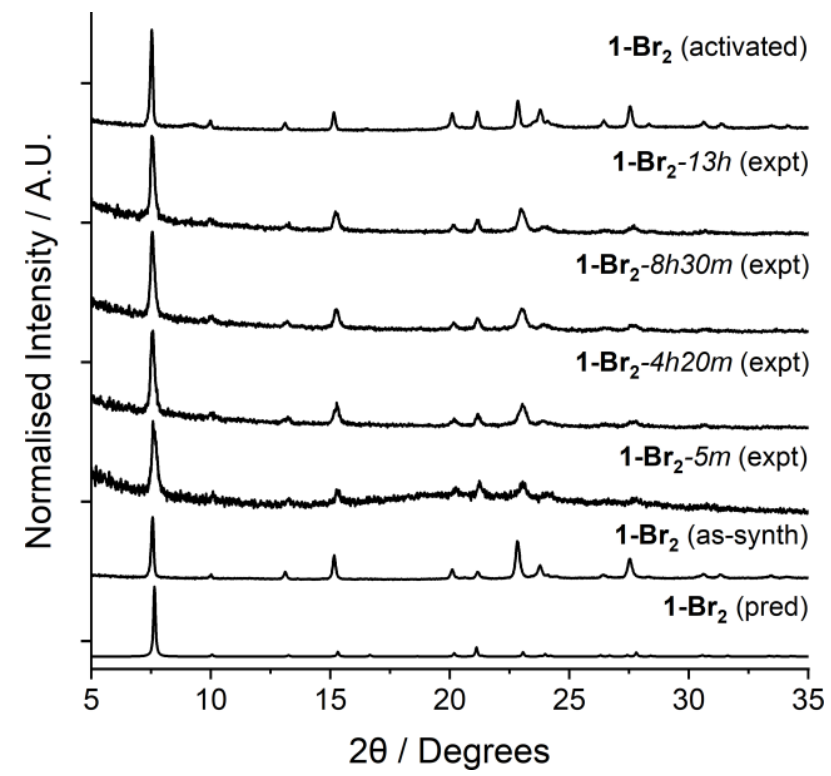

Figure 6. Stacked experimental powder $\mathrm{X}$-ray diffractograms of $\mathbf{1}-\mathbf{B r}_{\mathbf{2}}$ in the as-synthesised and activated forms, compared with the predicted pattern and a sample that was soaked in DMF and air dried (the time in the diffractogram label represents the drying time). All indicated no swelling/breathing behaviour on solvation and desolvation. 
Although both $\mathbf{1}$ and $\mathbf{2}$ are structurally independent, when $\mathbf{2}$ is subjected to the same bromination conditions it yields a material identical to $\mathbf{1}-\mathbf{B r}_{2}$ (SI, Section S8). For ease of analysis and interpretation, this product will be herein called $\mathbf{2}-\mathbf{B r}_{2}$, and displays an almost identical powder $\mathrm{X}$-ray diffractogram to $1-\mathbf{B r}_{2}$ (Figure $5 \mathrm{c}$ ). The presence of the alkene bond in the fumaric acid linker remains the key target for reaction of the bromine vapours, however, the formate bridges are also unexpectedly lost. Both the chemisorption of $\mathrm{Br}_{2}$ across both the double bond of fumarate, and the loss of the formate bridges are evident in the ${ }^{1} \mathrm{H}$ NMR spectrum of a digested sample, whereby the resonances at $\delta=6.6$ and $\delta=$ $8.1 \mathrm{ppm}$, assigned to the fumarate alkene protons and the formate protons, respectively, disappear following exposure to bromine, leaving a singlet at $\delta=4.5 \mathrm{ppm}$ assigned to the now $s p^{3}$ hybridised linker $\mathrm{C}-\mathrm{H}$ group (see SI, Figures S35 and S36). Bromination is also confirmed using Raman spectroscopy (Figure $5 \mathrm{~d}$ ). ${ }^{1} \mathrm{H}$ NMR spectra indicated the retention of DMF - around 0.75 molecules per SBU compared to one molecule per SBU in the parent material $\mathbf{2}$ - while TGA is also commensurate with a formula of $\left[\mathrm{Sc}_{3} \mathrm{O}\left(\mathrm{C}_{4} \mathrm{H}_{2} \mathrm{O}_{4} \mathrm{Br}_{2}\right)_{3}\left(\mathrm{H}_{2} \mathrm{O}\right)_{2}(\mathrm{OH})\right] \cdot\left(\mathrm{C}_{3} \mathrm{H}_{7} \mathrm{NO}\right)_{0.75}$ (observed $\mathrm{Sc}_{2} \mathrm{O}_{3}$ residue, $19.1 \%$ wt; predicted $\mathrm{Sc}_{2} \mathrm{O}_{3}$ residue, $19.1 \% \mathrm{wt}$ ). Elemental analysis again suggested adsorption of water prior to analysis, giving a formula for this sample of $2-\mathrm{Br}_{2}$ of $\left[\mathrm{Sc}_{3} \mathrm{O}\left(\mathrm{C}_{4} \mathrm{H}_{2} \mathrm{O}_{4} \mathrm{Br}_{2}\right)_{3}\left(\mathrm{H}_{2} \mathrm{O}\right)_{2}(\mathrm{OH})\right] \cdot\left(\mathrm{C}_{3} \mathrm{H}_{7} \mathrm{NO}\right)_{0.75} \cdot\left(\mathrm{H}_{2} \mathrm{O}\right)_{2}$. The theoretical bromine content for this composition $(43.0 \% \mathrm{wt})$ correlated well with the experimentally measured value $(43.5 \% \mathrm{wt})$, which is indicative of bromine only reacting across the double bonds (expected: $43.0 \%$ ), rather than bromide also replacing the formate as a coordinating counterion on the SBU (expected: $47.4 \%$ ). The halogenation step has also impacted the gas sorption properties; $\mathbf{2}$ exhibits a BET surface area for $\mathrm{N}_{2}$ at $77 \mathrm{~K}$ of $959 \mathrm{~m}^{2} \mathrm{~g}^{-1}$ but, like $\mathbf{1}-\mathbf{B r}_{2}, \mathbf{2}-\mathbf{B r}_{2}$ again shows negligible $\mathrm{N}_{2}$ uptake. The bromination of $\mathbf{1}$ and $\mathbf{2}$ therefore represents an unusual example whereby postsynthetic modification of two different MOFs results in the same final material.

\section{Conclusions}

In conclusion, we have shown that the continuous breathing behaviour of MIL-88A(Sc) (1) can be controlled both through direct synthetic methods as well as postsynthetic installation of linker functionality. By adjusting the reaction conditions for the modulated self-assembly of $\mathbf{1}$, a rigid and porous analogue, $\mathbf{2}$, can be synthesised. Whilst $\mathbf{1}$ exhibits the flexibility characteristic of its topology and closes on removal of pore-bound guests, $\mathbf{2}$ shows enhanced gas sorption properties as a consequence of bridging formate linkers buttressing the MOF enforcing structural rigidity. Quantitative postsynthetic bromination of the fumarate linkers in $\mathbf{1}$ and $\mathbf{2}$ yields, in each case, an identical product which exhibits structural rigidity resulting from the installation of sterically bulky bromine substituents across the linkers. As well as serving as an unusual example of two different 
MOFs being postsynthetically modified to form a uniform product, we have identified MIL-88A(Sc) as an efficient, irreversible adsorbent for $\mathrm{Br}_{2}$, as the dry MOF can theoretically chemisorb $0.88 \mathrm{~g} \mathrm{~g}^{-1} \mathrm{Br}_{2}$ vapour. In particular, the study highlights the extent of pre-and post-synthetic control that can be exercised over MOF flexibility and gas adsorption properties, offering new design principles and the ability to carefully tune breathing in highly-studied frameworks.

\section{Acknowledgements}

We thank the Royal Society for a University Research Fellowship (UF160394) and a Research Fellows Enhancement Award (RGF\EA (180077), and the EPSRC for funding (EP/N509668/1). We acknowledge the use of the ARCHER2 supercomputer through membership of the UK's HPC Materials Chemistry Consortium, which is funded by EPSRC grant number EP/R029431.

\section{Conflict of Interest}

The authors declare no conflict of interest. 


\section{References}

[1] H. Furukawa, K. E. Cordova, M. O'Keeffe and O. M. Yaghi, Science 2013, 341.

[2] a) J. Perles, M. Iglesias, M.-Á. Martín-Luengo, M. Á. Monge, C. Ruiz-Valero and N. Snejko, Chem. Mater. 2005, 17, 5837-5842; b) T. Kundu, B. B. Shah, L. Bolinois and D. Zhao, Chem. Mater. 2019, 31, 2842-2847.

[3] B. Yuan, X. Wang, X. Zhou, J. Xiao and Z. Li, Chem. Eng. J. 2019, 355, 679-686.

[4] M. Ranocchiari and J. A. van Bokhoven, Phys. Chem. Chem. Phys. 2011, 13, 6388-6396.

[5] a) S. Haddad, I. Abánades Lázaro, M. Fantham, A. Mishra, J. Silvestre-Albero, J. W. Osterrieth, G. S. Kaminski Schierle, C. F. Kaminski, R. S. Forgan and D. Fairen-Jimenez, J. Am. Chem. Soc. 2020, 142, 6661-6674; b) I. A. Lazaro and R. S. Forgan, Coord. Chem. Rev. 2019, 380, 230-259.

[6] F. Millange, C. Serre and G. Férey, Chem. Commun. 2002, 822-823.

[7] S. Surblé, C. Serre, C. Mellot-Draznieks, F. Millange and G. Férey, Chem. Commun. 2006, 284-286. [8] a) F. Carson, J. Su, A. E. Platero-Prats, W. Wan, Y. Yun, L. Samain and X. Zou, Cryst. Growth Des. 2013, 13, 5036-5044; b) P. Horcajada, F. Salles, S. Wuttke, T. Devic, D. Heurtaux, G. Maurin, A. Vimont, M. Daturi, O. David and E. Magnier, J. Am. Chem. Soc. 2011, 133, 17839-17847; c) G. Férey and C. Serre, Chem. Soc. Rev. 2009, 38, 1380-1399; d) M. de J. Velásquez-Hernández, V. B. López-Cervantes, E. Martínez-Ahumada, M. Tu, U. Hernández-Balderas, D. Martínez-Otero, D. R. Williams, V. Martis, E. Sánchez-González, J.-S. Chang, J. Sun Lee, J. Balmaseda, R. Ameloot, I. A. Ibarra and V. Jancik, Chem. Mater. 2022, 34, 669-677; e) J. Troyano, A. Carné-Sánchez, J. Pérez-Carvajal, L. León-Reina, I. Imaz, A. Cabeza and D. Maspoch, Angew. Chem. Int. Ed. 2018, 57, 15420-15424.

[9] C. Mellot-Draznieks, C. Serre, S. Surblé, N. Audebrand and G. Férey, J. Am. Chem. Soc. 2005, 127, $16273-16278$.

[10] C. Serre, C. Mellot-Draznieks, S. Surblé, N. Audebrand, Y. Filinchuk and G. Férey, Science 2007, $315,1828-1831$.

[11] J.-P. Zhang, H.-L. Zhou, D.-D. Zhou, P.-Q. Liao and X.-M. Chen, Nat. Sci. Rev. 2018, 5, 907-919.

[12] S. Henke, A. Schneemann, A. Wütscher and R. A. Fischer, J. Am. Chem. Soc. 2012, 134, 9464-9474. [13] S. M. Cohen, Chem. Rev. 2012, 112, 970-1000.

[14] a) K. K. Tanabe, C. A. Allen and S. M. Cohen, Angew. Chem. Int. Ed. 2010, 49, 9730-9733; b) Z. Wang and S. M. Cohen, Angew. Chem. Int. Ed. 2008, 47, 4699-4702; c) Y. Zhang, X. Feng, H. Li, Y. Chen, J. Zhao, S. Wang, L. Wang and B. Wang, Angew. Chem. Int. Ed. 2015, 54, 4259-4263.

[15] E. J. Carrington, S. F. Dodsworth, S. van Meurs, M. R. Warren and L. Brammer, Angew. Chem. Int. Ed. 2021, 60, 17920-17924.

[16] S. C. Jones and C. A. Bauer, J. Am. Chem. Soc. 2009, 131, 12516-12517. 
[17] a) R. J. Marshall, S. L. Griffin, C. Wilson and R. S. Forgan, J. Am. Chem. Soc. 2015, 137, 9527-9530; b) R. J. Marshall, T. Richards, C. L. Hobday, C. F. Murphie, C. Wilson, S. A. Moggach, T. D. Bennett and R. S. Forgan, Dalton Trans. 2016, 45, 4132-4135; c) R. J. Marshall, S. L. Griffin, C. Wilson and R. S. Forgan, Chem. Eur. J. 2016, 22, 4870-4877.

[18] X. Xu, F. Yang, S.-L. Chen, J. He, Y. Xu and W. Wei, Chem. Commun. 2017, 53, 3220-3223.

[19] a) R. J. Marshall, C. T. Lennon, A. Tao, H. M. Senn, C. Wilson, D. Fairen-Jimenez and R. S. Forgan, J. Mater. Chem. A 2018, 6, 1181-1187; b) R. S. Forgan, Chem. Sci. 2020, 11, 4546-4562.

[20] P. Wang, L. Zhang, Z. Zhu, S. Wu, L. Shan, Y. Fan, L. Wang, X. Chen and J. Xu, Inorg. Chim. Acta 2020, 501, 119304.

[21] a) M.-H. Pham, G.-T. Vuong, A.-T. Vu and T.-O. Do, Langmuir 2011, 27, 15261-15267; b) T. Rijnaarts, R. Mejia-Ariza, R. J. Egberink, W. van Roosmalen and J. Huskens, Chem. Eur. J. 2015, 21, 10296-10301.

[22] A. C. McKinlay, J. F. Eubank, S. Wuttke, B. Xiao, P. S. Wheatley, P. Bazin, J. C. Lavalley, M. Daturi, A. Vimont, G. De Weireld, P. Horcajada, C. Serre and R. E. Morris, Chem. Mater. 2013, 25, 1592-1599. [23] a) R. R. Prasad, C. Pleass, A. L. Rigg, D. B. Cordes, M. M. Lozinska, V. M. Georgieva, F. Hoffmann, A. M. Slawin and P. A. Wright, CrystEngComm 2021, 23, 804-812; b) R. R. Prasad, S. E. Seidner, D. B. Cordes, M. M. Lozinska, D. M. Dawson, M. J. Thompson, T. Düren, K. K. Chakarova, M. Y. Mihaylov and K. I. Hadjiivanov, J. Mater. Chem. A 2019, 7, 5685-5701; c) S. Miller, P. Wright, T. Devic and C. Serre, Langmuir 2009, 25, 3618; d) R. S. Pillai, V. Benoit, A. Orsi, P. L. Llewellyn, P. A. Wright and G. Maurin, J. Physi. Chem. C 2015, 119, 23592-23598.

[24] a) L. Du, Z. Lu, K. Zheng, J. Wang, X. Zheng, Y. Pan, X. You and J. Bai, J. Am. Chem. Soc. 2013, 135, 562-565; b) J. D. Humby, O. Benson, G. L. Smith, S. P. Argent, I. Da Silva, Y. Cheng, S. Rudić, P. Manuel, M. D. Frogley and G. Cinque, Chem. Sci. 2019, 10, 1098-1106.

[25] a) I. A. Ibarra, S. Yang, X. Lin, A. J. Blake, P. J. Rizkallah, H. Nowell, D. R. Allan, N. R. Champness, P. Hubberstey and M. Schröder, Chem. Commun. 2011, 47, 8304-8306; b) I. A. Ibarra, X. Lin, S. Yang, A. J. Blake, G. S. Walker, S. A. Barnett, D. R. Allan, N. R. Champness, P. Hubberstey and M. Schröder, Chem. Eur. J. 2010, 16, 13671-13679.

[26] N. Wei, R.-X. Zuo, Y.-Y. Zhang, Z.-B. Han and X.-J. Gu, Chem. Commun. 2017, 53, 3224-3227.

[27] T. J. M. M. Ntep, H. Reinsch, J. Liang and C. Janiak, Dalton Trans. 2019, 48, 15849-15855.

[28] I. Roberts and G. E. Kimball, J. Am. Chem. Soc. 1937, 59, 947-948. 